\title{
The quantitative separation of meiofauna
}

\author{
A comparison of methods \\ G. UHLIG ${ }^{1}$, H. ThIEL ${ }^{2} \&$ J. S. GRAY ${ }^{3}$ \\ 1 Biologische Anstalt Helgoland (Meeresstation); \\ Helgoland, Federal Republic of Germany \\ and \\ 2 Institut für Hydrobiologie und Fischereiwissenschaft, Universität Hamburg; \\ Hamburg, Federal Republic of Germany \\ and \\ 3 University of Leeds, Wellcome Marine Laboratory; \\ Robin Hood's Bay, Yorkshire, England
}

KURZFASSUNG: Die quantitative Isolierung der Meiofauna. Ein Methodenvergleich. Im Mai 1972 fand an der Meeresstation der Biologischen Anstalt Helgoland ein Arbeitstreffen mit dem Ziel statt, die verschiedenen Methoden zur quantitativen Isolierung der Meiofauna aus dem Sediment in ihrer Effektivität miteinander zu vergleichen. Die Verfahren zur Anreicherung der Meiofauna in der Probe, des Sortierens und Auszählens werden beschrieben und die durch die Teilnehmer am Arbeitstreffen gemeinsam erzielten Ergebnisse diskutiert. Die Wertung der einzelnen Methoden zur Erfassung der Gesamtfauna, der "harten" und der "weichen" Meiofauna, von konservierten und nichtkonservierten Organismen sowie die Anwendung der Methoden auf verschiedene Sedimenttypen werden durch statistische Analysen abgesichert. Eine Zusammenfassung der Arbeitsverfahren sowie deren Charakterisierung und Leistungsfähigkeit beschließt die Darstellung.

\section{INTRODUCTION}

Within the last few decades investigation of meiobenthos has been intensified. Originally, studies were limited to microporal interstitial sediments. Later, however, other littoral and sublittoral sediments, e.g. mud and clay, were investigated. Today, not only the meiobenthos of shallow waters but also that of deep-sea environments is being studied.

Many efforts have been made to overcome the methodological difficulties involved in meiobenthos handling. Primarily, these include sampling and separation of the small-sized and delicate specimens. As far as qualitative studies are concerned, the difficulties can be overcome by various means with a reasonable expenditure of time. However, during recent years, quantitative aspects concerning studies on distribution, abundance, migration, fluctuation and other dynamics and ecological processes of the 
meiofauna have become increasingly important. Consequently, separation procedures have become more laborious, with the need for extra precision.

In 1969, the Mediterranean Marine Sorting Center in Salammbo, Tunisia, invited several meiobenthologists to discuss the central problems in meiofauna investigations. The results of this meeting were published in the "Manual for the study of meiofauna" (Hulings \& GRAY 1971). This manual represents the first attempt to summarize recent experience in this field. Many recommendations are given for the measurement of environmental parameters, sampling and separation of the meiofauna from the sediment, as well as preparation methods for the main representative groups of meiofauna. In the foreword of the "Proceedings of the First International Conference on Meiofauna" Hulings (1971) pronounces: "Statistical evaluation of various techniques of sampling ... are imperative." Yet, concerning separation methods, no comparison could be made during this Tunisia meeting. For the separation of meiofauna several methods have been published which essentially are modifications of a few basic procedures. Generally, the choice of a suitable method depends on the aim of the scientific problem studied. This includes the decision, whether the meiofauna (certain species, important representatives, or the total meiofauna) has to be separated alive, or whether it can be handled preserved.

The efficiency of the commonly used methods has been evaluated with varying results by different authors. However, no statistical analyses are available which can offer reliable comparisons. In order to solve this problem a number of specialists were invited to a meeting. All the participants were asked to present their quantitative separation procedures for comparison, using replicate samples.

This meeting was held on Helgoland at the Marine Station of the Biologische Anstalt Helgoland from May $4^{\text {th }}$ to May 12th 1972 , in co-operation with the working group on meiofauna of the Baltic Marine Biologists (Convenor: $\mathrm{H}$. THIEL). The participants at the Helgoland meeting, who are listed on page 194, have authorised us to present here the data and results obtained in close comoperation and discussion at that meeting.

\section{DESCRIPTION OF THE SEPARATION METHODS USED}

Separation of meiofauna from the sediment involves two different procedures: (1) concentration and (2) sorting and counting. We define these terms as follows: Concentration: The enrichment of meiofauna in respect of sediment particles in the sample. Sor $\mathrm{t}$ ing and c o u $\mathrm{n}$ in $\mathrm{g}$ : The classification of fauna into taxonomical groups and the counting of specimens.

The essential methodological differences are restricted to the concentration procedure. These will be described therefore in separate sections, while sorting and counting as done by the participants is combined in one paragraph. Concentration methods are based largely on the hydrodynamic behaviour of the sediment particles. This depends on different characteristics of the particles: Size, specific weight, form and surface structure. Sinking rate and transport by water flow are determined by such characteristics. Since there is no suitable short expression for particles with different hydro- 
dynamic behaviour we have used the terms, "lighter" particles and "heavier" particles in the subsequent text. These terms may be defined as: "lighter" particles, those with a low sinking rate or easily transported by a definite water flow and "heavier" particles those with a high sinking rate or less easily transported by the same water flow.

\section{Concentration of meiofauna}

\section{Decantation and sieving}

The method of decantation and sieving was practised by R. ELMGREN (EL) and H. THIEL (TH). The most simple treatment for the concentration of meiofauna specimens in a sediment sample is decantation. The sample is stirred up in a dish, glass beaker or measuring glass. After allowing a short time for settlement of "heavier" sand grains or other constituents of the sample, the supernatant water is poured out through a sieve or a set of sieves. Larger particles, including the organisms wanted, are retained, while mud particles pass through. This procedure may be repeated several times until most or all of the fauna is washed out of the coarse fraction of the sample. Repeated decantation and subsequent sorting and counting allows an estimation of the efficiency of the procedure, since the residue can be checked periodically. In total fauna separation, decantation is applied generally for preserved material.

Concentration by sieving is restricted to the separation of a coarser fraction containing the organisms and the finer fraction, which is discarded. The mesh size of the sieve used depends on the size of animals to be considered in the investigation. The sieving of the coarser fraction into size groups makes sorting and counting easier and more efficient (p. 180) but no concentration effect is achieved. Normally, both these treatments are combined into one procedure.

\section{Elutriation methods}

The elutriation method was introduced by Borsseau (1957). In the years following, this method has been used for sandy sediments by several authors and the equipment has changed slightly. The general idea is the partition of particles by their different characteristics in response to a continous water stream. The "lighter" particles, including the meiofauna organisms, are washed out of the sample and are collected on a sieve.

(a) Modifications of the BoIsseau method. Elutriation methods of the Boisseau type were practised by I. Drzycrmskr (DR), J. S. Gray (GR), and A. D. McIntyre (McI) in 3 modifications. Two of them used preserved (McI) or unpreserved (DR) material in an open water stream while in the third apparatus (GR) a closed water circuit was used for narcotized living organisms. The essential part of the apparatus (Fig. 1) is a separation funnel which contains the sample. The open circuit system is connected to the main cold-water supply or to some filtered sea-water reservoir. The water stream passes through the separation funnel, containing the 
sample, and the overflow tube. The meiofauna washed out of the sample is concentrated on the sieve. In the closed-circuit system a water pump circulates water from a reservoir. The flow rates are adjusted by the two valves.

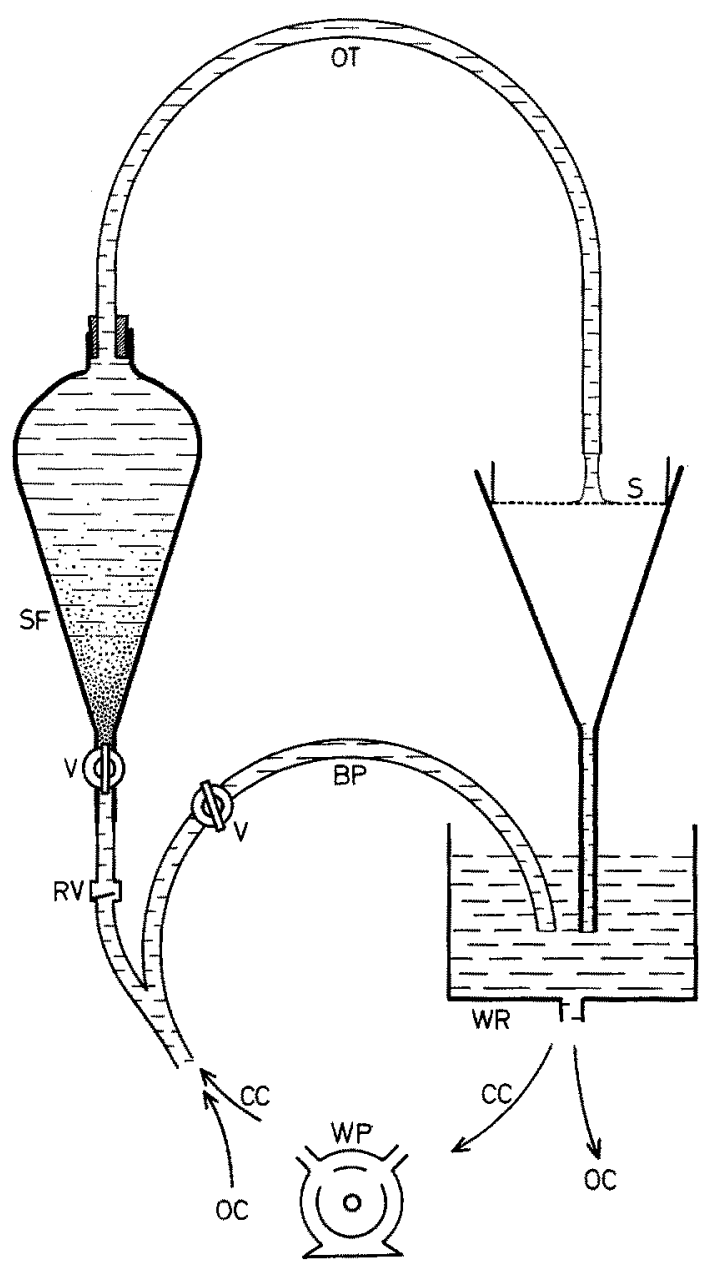

Fig. 1: Elutriation apparatus, combined for open and closed system. BP; by-pass, CC: closed circuit, OC: open circuit, OT: overflow tube, RV: reflex valve, S: sieve, SF: separation funnel, V: valve, WP: water pump, WR: water reservoir

Preserved material is stained (p. 179) and the subsequent elutriation cleans the material of excess stain. If the meiofauna is to be concentrated alive, the closed-circuit system is essential and the organisms will be narcotized by means of an anaesthetic ( $7 \% \mathrm{MgCL}_{2}$ in water).

In the case of $(\mathrm{McI})$, the apparatus was connected to the main cold-water supply and elutriation was carried out for 15 minutes per sample, the flow being regulated so that the sediment was well agitated but was not carried over onto the sieve in any 
great quantity. The animals retained on the 45 micron sieve were then washed into a $9 \mathrm{~cm}$ diameter bacteriological Petri dish (or a $14 \mathrm{~cm}$ diameter dish when faunal density was high), dispersed with water from a wash bottle, allowed to settle and counted.

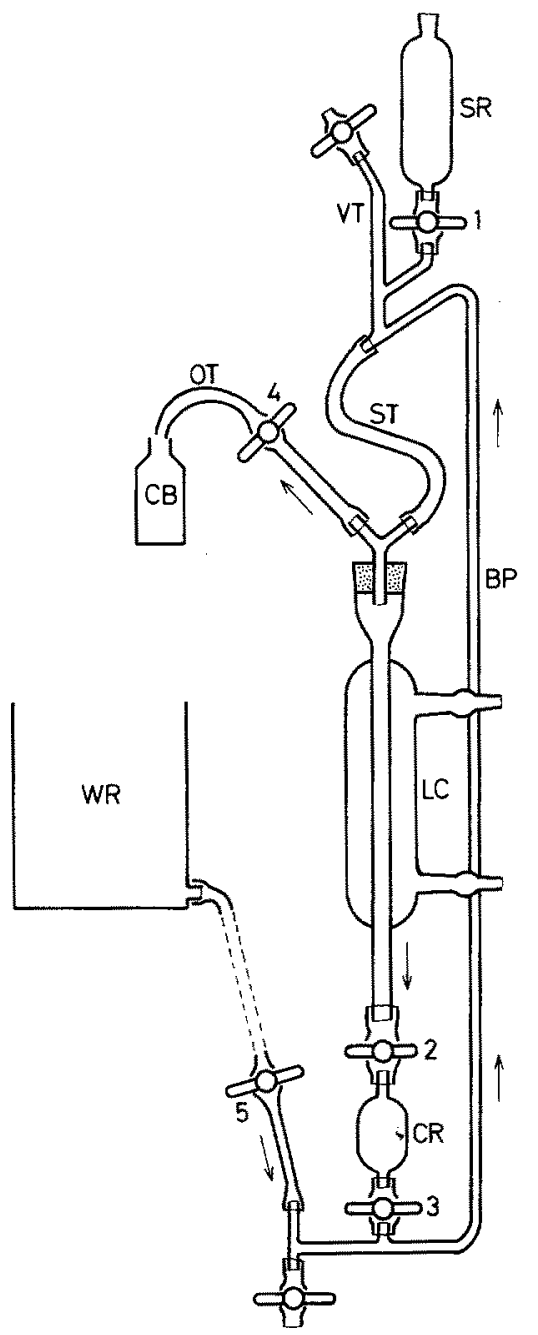

Fig. 2: Apparatus for warm-water elutriation. BP: by-pass, CB: collecting bottle, CR: collecting receptacle, LC: Liebig condensor, OT: overflow tube, SR: sample receptacle, ST: settling tube, VT: ventilation tube, WR: water reservoir, 1-5: valves. (After OHDE, unpublished)

Because of the much higher proportion of silt in the muddy sand sample, elutriation rates were reduced so that small fractions of the total sample could be examined separately. Thus, the sample was examined in 4 or 5 fractions in which the numbers of animals decreased very substantially with each successive "washing". The amount of material "washed off" in any one fraction was controlled, so that the sediment deposit 
in the petri dish would not obscure fauna for the scanning operation. Total elutriation time was approximately the same as for other sediments.

(b) The warm-water elutriation. The warm-water elutriation was designed and practised by J. OHDE (OH) (unpublished). The apparatus (Fig. 2) consists of the receptacle for the sample, connected by a spiral settling tube with a Liebig condensor. At its lower end a collecting receptacle connects to a water in- and outlet, as well as to a by-pass which runs back into the settling tube. The overflow tube leads into the collecting bottle or a sieve.

In the concentration procedure, the whole system is first filled with filtered water from the reservoir. The sample is rinsed into the sample receptacle and, by opening of the valves 1 and 2 , is allowed to flow down the settling tube and to sink through the inner pipe of the condensor into the collection receptacle. The jacket tube of the condensor is charged with water of $55^{\circ} \mathrm{C}$ constant temperature. By this means the fluid and the sample in the inner tube of the condensor are warmed. Under these conditions nematodes are stretched and ostracods open their shells, resulting in a higher water resistance, i.e. a better separation efficiency. After closing valve 2 and opening valves 3,4 , and 5 , water flow from the reservoir carries the particles up the by-pass into the spiral settling tube. The water stream transports the "lighter" particles and fauna via the overflow tube into the collecting bottle. "Heavier" particles run slowly down the wall of the spiral settling tube and again sink down the condensor. The flow rate is regulated by changing the vertical position of the sample receptacle. The procedure can be repeated at will. Air bubbles originating from gases dissolved in the water may be let out of the system through the ventilation tube. Finally, the sediment and the water are drained out of the apparatus and the tubes are washed thoroughly. For maximum efficiency, the water may be run through a sieve to collect specimens stuck to the tube walls.

\section{Sea-water ice treatment}

This method was practised by E. HARTwig \& S. HoxhoLd $(\mathrm{HH})$ and by G. UnLIG (UH). The sea-water ice treatment, described by UHLIG $(1964,1968)$, is based on changing the intensity of environmental factors in the sediment samples treated. The infauna of a sample is influenced mainly by two ecological parameters: (1) The change from high to low salinity of melting sea water and (2) a low perfusion and flow of water through the sediment. Temperature, also, may have a slight effect. Under these conditions the interstitial fauna migrates actively out of the sediment and is collected alive in a culture dish, almost free of sediment.

One end of a plastic tube (Fig. 3) is covered with a tightly fitting nylon gauze, the mesh size of which depends on the main grain size and then the tube is filled with crushed sea-water ice, prepared in a deep freezer. Insulation is placed between sediment and ice. A Petri- or culture dish, filled with filtered sea water, is placed under the tube so that the nylon gauze is just in contact with the sea-water surface. Both the culture dish and the tube are in a fixed position. The Petri dish is placed in a second larger one, into which the water can overflow. Plastic tubes of different size and diameter were used by $(\mathrm{HH})$ and $(\mathrm{UH})$. In that way, $(\mathrm{HH})$ exposed a larger sediment surface 
to ice. Furthermore, by application of a larger volume of sea-water ice, the treatment with ice was intensified.

The sea-water ice treatment is most effective in sandy sediments, e.g. if the sediment has a capillary structure. In the case of muddy sediments, the treatment of prepartitioned sediment fractions is possible. The efficiency can be raised by repeated extraction as well as by a two-part technique with decantation or elutriation (p. 190) following the ice-treatment procedure.

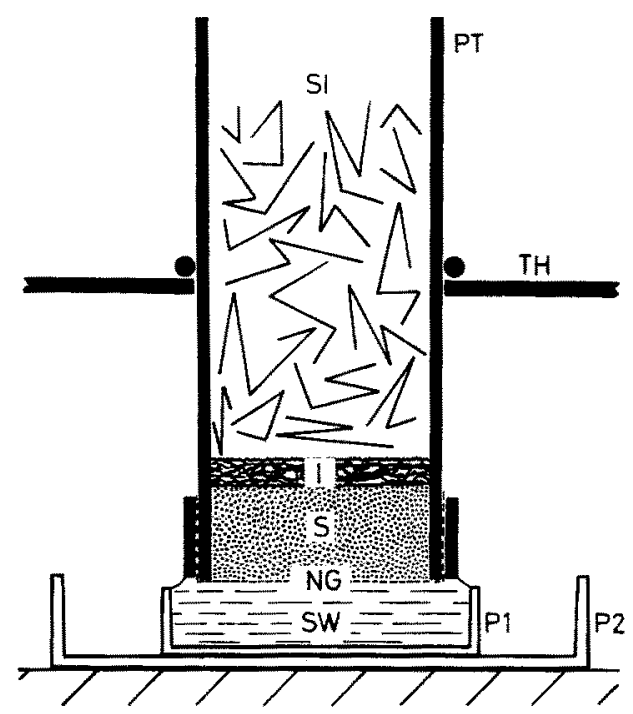

Fig. 3: Sea-water ice treatment. I: Insulation material, NG: nylon gauze, P1, P2: Petri- or culture dishes, PT: Plastic tube, S: Sediment, SI: Sea-water ice, SW: Sea water, TH: Tube holder

\section{Sorting and counting of meiofauna}

Sorting and counting under a stereoscopic microscope is common to all the separation methods tested. Only small differences were encountered between the procedures of the participants but personal experience is important. This part is, therefore, described together in one paragraph.

For preservation 4-5\% formalin was used for at least 20 minutes. In samples to be stored for a long time the formalin should be neutralized with $100 \mathrm{~g}$ hexamethylene tetramine per $1000 \mathrm{~cm}^{3}$ of $40 \%$ formaldehyde. After washing out the formalin, the sample was stained with rose bengal + phenol (THIEL 1966) for at least 15 minutes.

$\mathrm{Sta}$ ining solution: $100 \mathrm{ml}$ of water $+1 \mathrm{ml}$ of concentrated rose bengal solution $+5 \mathrm{ml}$ of concentrated aqueous solution of phenol (for $\mathrm{pH}$ adjustment).

Stain ing procedure: (1) The sample is washed from the sampling bottle into a sieve of the smallest mesh size required in the respective research. (2). The sample is rinsed in a beaker of tap water until no preservation fluid remains. (3) The sample in 
the sieve is placed in the staining solution for about 15 minutes. (4) The sample in the sieve is again rinsed either in a beaker of tap water until the water is not coloured immediately or by elutriation.

Staining was followed either by direct sorting and counting or by elutriation or decantation, described in the previous section under methods for concentration. Mechanical hand counters were used to record numerically dominant groups.

In the case of $(\mathrm{Mcl})$ animals were counted in situ in the dish and organisms were extracted (by pipette) only when identification under high-power microscope was required. Counting was carried out with a Petri dish resting on a squared paper grid $(1 \mathrm{~cm}$ square units) and using a Vickers Extenda-arm scanning microscope, $20 \times$ magnification. The field of view is thus approximately $1 \mathrm{~cm}^{2}$. In this way, with the Petri dish fixed in position, the bottom of the dish and the surface of the water can be systematically scanned. In situ counting is less time consuming than the simultaneous extraction of the organisms with a pipette (which all other participants did and Petri dishes were used for sorting under stereoscopic microscopes).

With decantation, (EL) produced 2 fractions of $100 \mu \mathrm{m}$ and $37 \mu \mathrm{m}$. These were transferred to a Bogorov-tray (Russell \& Colman 1931, ARLt 1973). The tray was carefully searched and all animals found picked out. The contents of the tray were then thoroughly agitated with the pipette, and allowed to settle before a new search was made. This was repeated once more, so that three searches were made for each portion examined, and the animals found in each search noted (further discussion in ELMGREN 1973).

The decantation technique omitted the sorting of coarse fractions. Instead, small fractions were used by (TH) but all the sediment was searched through, as indeed has to be done with very fine-grained sediments such as deep-sea oozes. Before sorting and counting, the samples were sieved into four fractions of $>42,>65,>100$ and $>150 \mu \mathrm{m}$. Working with a narrow grain-size range was found to be more effective. Small dishes were used with the stereoscopic microscope and limited portions were sorted successively in order to produce a thin sediment layer in the dish. The samples were sorted twice.

\section{SAMPLING, SEDIMENT ANALYSES AND FAUNA}

It was the intention of the working group to analyse the efficiency of the methods on a wide spectrum of sediments. Within the available time we were able to study four different types of substrata (Fig. 4). The sediments from each of the three sublittoral stations were homogenized by manual mixing to omit natural variability between samples, while the samples from the beach were taken in situ.

\section{Sediment data and handling}

(1) Medium sand with fine sand, well sorted - termed medium sand (Fig. 4a); Helgoland Reede - near Youth Hostel; Sublittoral, 6-8 m. The material was collected by divers scraping surface sediment into buckets. In a constant-temperature 

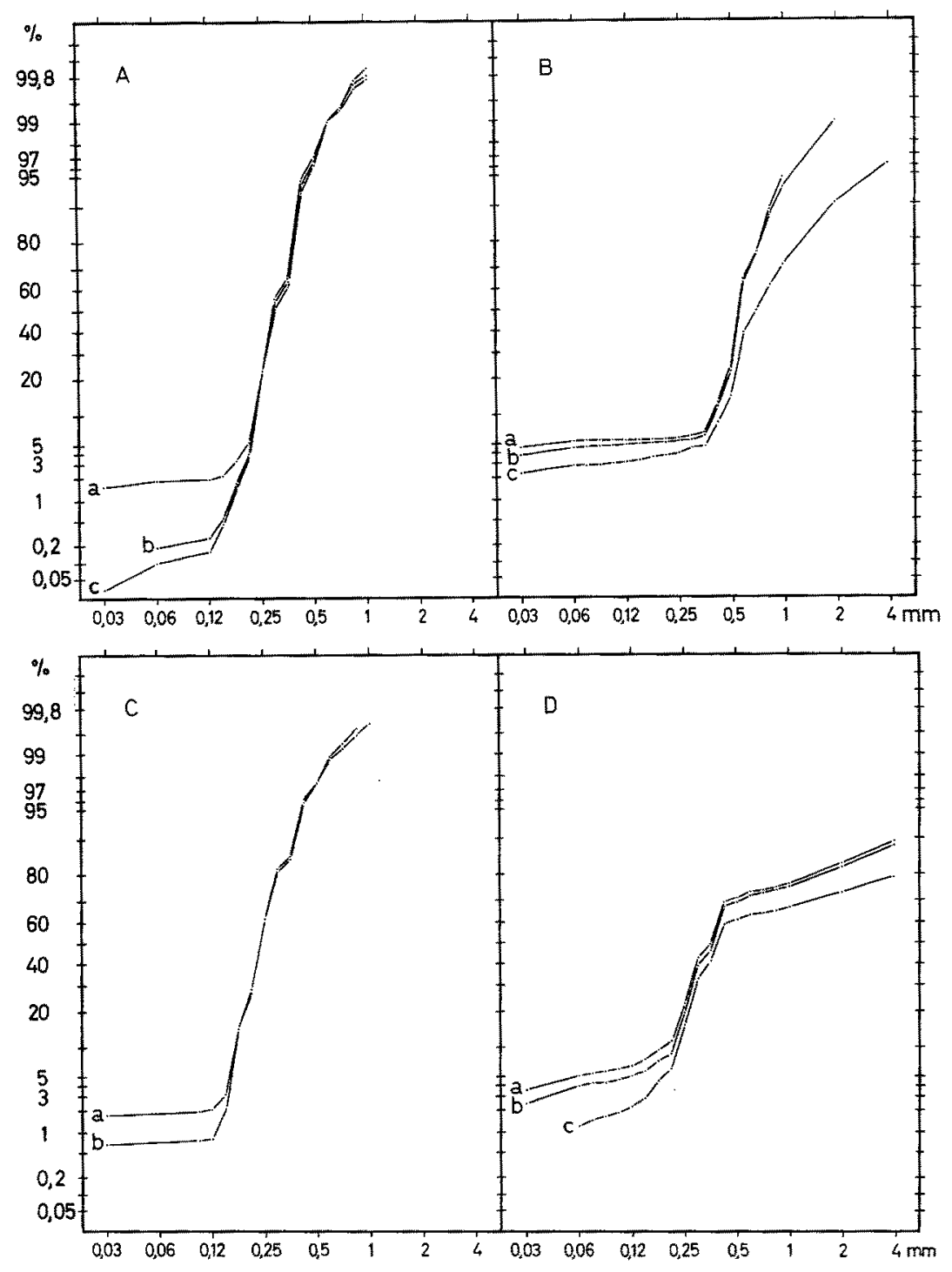

Fig. 4: Cumulative grain-size curve for the four types of sediments used in the experiments. $A$ Medium sand with fine sand, well sorted. (a) $\mathrm{Q}_{1}=259, \mathrm{Q}_{8}=366, \mathrm{Md}=291$, So $=1,19$; (b) $\mathrm{Q}_{1}=259, \mathrm{Q}_{3}=361, \mathrm{Md}=287$, So $=1,18 ;(c) \mathrm{Q}_{1}=260, \mathrm{Q}_{3}=379, \mathrm{Md}=297$, So $=1,12$; (abbreviation: Medium sand, corresponding to Tables 3, 7, 10). $B$ Coarse sand with shell gravel, fairly well sorted. (a) $\mathrm{Q}_{1}=493, \mathrm{Q}_{3}=702, \mathrm{Md}=563$, So $=1,19 ;(b) \mathrm{Q}_{1}=$ $507, \mathrm{Q}_{3}=707, \mathrm{Md}=563$, So $=1,18 ;(c) \mathrm{Q}_{1}=543, \mathrm{Q}_{3}=889, \mathrm{Md}=707$, So $=1,28$; (abbreviation: coarse sand, corresponding Tables 4, 8, 11). C Fine sand, well sorted. (a) $\mathrm{Q}_{1}=$ $203, \mathrm{Q}_{3}=277, \mathrm{Md}=233$, So $=1,16$; (b) $\mathrm{Q}_{1}=203, \mathrm{Q}_{3}=279, \mathrm{Md}=237$, So $=1,17$; (abbreviation: fine sand, corresponding to Table 6). D Medium sand with fine sand, less sorted. (a) $\mathrm{Q}_{1}=254, \mathrm{Q}_{3}=841, \mathrm{Md}=354$, $\mathrm{So}=1,82 ;(b) \mathrm{Q}_{1}=259, \mathrm{Q}_{3}=637, \mathrm{Md}=337$, So $=1,57$; (c) $\mathrm{Q}_{1}=277, \mathrm{Q}_{3}=229, \mathrm{Md}=384$, So $=2,88$; (abbreviation: muddy sand, corresponding to Tables $5,9,12$ ) 
room $\left(15^{\circ} \mathrm{C}\right)$, the sediment was transferred into a tank of $50 \times 90 \mathrm{~cm}$ under intensive manual mixing.

For sampling, a grid was laid over the tank with $4 \times 8$ fields of $10 \times 10 \mathrm{~cm}$, leaving $5 \mathrm{~cm}$ margin around the tank. The 4 longitudinal rows, each with 8 fields, are called levels A, B, C, D (Fig. 5). Sediment was cored from each field centre. For statistical analyses the distribution of samples between participants was arranged according to a table of random numbers. Each method received 4 samples, one from each level. The samples covered a surface area of $4 \mathrm{~cm}^{2}$ and reached $4 \mathrm{~cm}$ into the sediment.

\begin{tabular}{|c|c|c|c|c|c|c|c|c|c|}
\hline & 1 & 2 & 3 & 4 & 5 & 6 & 7 & 8 \\
\hline A & $\mathrm{MCl}$ & $\mathrm{OH}$ & $\mathrm{HH}$ & $\mathrm{UH}$ & $\mathrm{EL}$ & $\mathrm{TH}$ & $\mathrm{GR}$ & $\mathrm{DR}$ \\
& 378 & 171 & 593 & 513 & 664 & 272 & 480 & 404 & \\
\hline \multirow{2}{*}{$\mathrm{B}$} & $\mathrm{UH}$ & $\mathrm{DR}$ & $\mathrm{GR}$ & $\mathrm{TH}$ & $\mathrm{MCl}$ & $\mathrm{EL}$ & $\mathrm{OH}$ & $\mathrm{HH}$ & \\
& 393 & 346 & 242 & 351 & 260 & 410 & 258 & 823 & \\
\hline \multirow{2}{*}{$\mathrm{C}$} & $\mathrm{OH}$ & $\mathrm{HH}$ & $\mathrm{GR}$ & $\mathrm{DR}$ & $\mathrm{TH}$ & $\mathrm{UH}$ & $\mathrm{MCl}$ & $\mathrm{EL}$ & \\
& 197 & 321 & 215 & 342 & 335 & 482 & 796 & 1013 & \\
\hline \multirow{2}{*}{$\mathrm{D}$} & $\mathrm{EL}$ & $\mathrm{DR}$ & $\mathrm{MCl}$ & $\mathrm{UH}$ & $\mathrm{GR}$ & $\mathrm{TH}$ & $\mathrm{OH}$ & $\mathrm{HH}$ & \\
& 1192 & 278 & 932 & 569 & 391 & 553 & 397 & 399 & \\
\hline & & & & & & & & & \\
\hline
\end{tabular}

Fig. 5: Pattern of random sample distribution of the coarse-sand sediment (Table 4). Longitudinal: levels A-D; vertical: rows $1-8$. The figures within the fields represent the total number of animals found by the different methods as marked by symbols

3 larger samples for grain-size analyses were removed from the tanks on a diagonal line after the test samples had been removed. A relatively homogenous grain-size distribution was achieved by the manual mixing as demonstrated in Figures $4 a, 4 b$ and $4 \mathrm{~d}$.

(2) Coarse sand with shell gravel, fairly well sorted - termed coarse sand (Fig. 4b); Helgoland Reede - Skittgatt; Sublittoral, 4-5 m. Handling of material was as for sediment 1.

(3) Fine sand, well sorted - termed fine sand (Fig. 4c); Helgoland Düne; Littoral near low-water tide mark. Samples were taken from an area of $70 \times 80 \mathrm{~cm}$ marked out with a grid of $10 \times 10 \mathrm{~cm}$. In total, 42 aliquot samples were cut out with a corer from each point of intersection. Five samples of $4 \mathrm{~cm}^{2}$ surface area and $4 \mathrm{~cm}$ sediment depth, randomly distributed within each level, were used in each separation method.

The material for the 2 grain-size analyses was collected each from one square 10 by $10 \mathrm{~cm}$ and $10 \mathrm{~cm}$ sediment depth. One sample originated from a corner of the grid towards the sea, the other from the diagonal corner, higher up the beach. The grain-size distribution for both the samples is very similar (Fig. 4c) indicating that the material within the grid is quite homogenous.

(4) Medium sand with fine sand, less sorted - termed muddy sand (Fig. 4d); Helgoland Vorhafen; Sublittoral, 5-7 m. Handling of material was as for sediment 1. 


\section{Frequency of taxa}

In order to demonstrate the frequency of occurrence of the different taxa, the number of organisms counted by the eight methods are listed in Table 1. Table 1 also illustrates the high variation between the methods for certain taxa. Table 2 gives the

Table 1

Number of organisms counted per taxon, and different methods used on coarse sand with shell gravel. Abbreviations see text

\begin{tabular}{|c|c|c|c|c|c|c|c|c|c|c|}
\hline \multirow{2}{*}{ Taxa } & \multicolumn{2}{|c|}{$\begin{array}{l}\text { Decantation } \\
\text { total sorting }\end{array}$} & \multirow[b]{2}{*}{ DR } & \multicolumn{2}{|c|}{ Elutriation } & \multirow[b]{2}{*}{$\mathrm{OH}$} & \multicolumn{2}{|c|}{$\begin{array}{l}\text { Sea-water ice } \\
\text { technique }\end{array}$} & \multirow{2}{*}{ Total } & \multirow{2}{*}{$\% / 0$} \\
\hline & $\mathrm{EL}$ & TH & & GR & McI & & $\mathrm{HH}$ & UH & & \\
\hline Ciliata & 109 & & & & & & 56 & 155 & 320 & \\
\hline Turbellaria & 666 & 177 & 170 & 132 & 425 & & 598 & 320 & 2488 & 16.6 \\
\hline Gastrotricha & 210 & 75 & 28 & 29 & 114 & & 97 & 77 & 630 & 4.2 \\
\hline Nematoda & 592 & 361 & 175 & 283 & 349 & 268 & 331 & 392 & 2751 & 18.4 \\
\hline Archiannelida & 58 & 8 & 5 & 6 & 35 & & 46 & 13 & 171 & \\
\hline Polychaeta & 28 & 20 & 31 & 28 & 30 & 4 & 33 & 25 & 199 & \\
\hline Copepoda & 48 & 16 & 31 & 26 & 30 & 28 & 28 & 23 & 230 & \\
\hline Nauplii & 28 & 55 & 4 & 1 & 7 & 2 & 7 & 9 & 113 & \\
\hline Ostracoda & 1565 & 717 & 842 & 777 & 1335 & 671 & 933 & 1028 & 7868 & 52.5 \\
\hline Halacarida & 63 & 62 & 79 & 43 & 30 & 39 & 32 & 60 & 408 & 2.7 \\
\hline Others & 21 & 20 & 5 & 3 & 11 & 11 & 31 & 10 & 112 & \\
\hline \multicolumn{11}{|l|}{$\begin{array}{l}\text { Total } \\
\text { without }\end{array}$} \\
\hline Ciliata & 3279 & 1511 & 1370 & 1. 328 & 2366 & 1023 & 2136 & 1957 & 14970 & \\
\hline
\end{tabular}

Table 2

Total number of organisms counted per sediment type. Individual numbers for the fine-sand sample from Helgoland Düne apply to a sediment surface area of $104 \mathrm{~cm}^{2}$ and $4 \mathrm{~cm}$ sediment depth

\begin{tabular}{|c|c|c|c|c|c|c|c|c|}
\hline \multirow{2}{*}{ Taxa } & \multicolumn{2}{|c|}{ Medium sand } & \multicolumn{2}{|c|}{ Coarse sand } & \multicolumn{2}{|c|}{ Fine sand } & \multicolumn{2}{|c|}{ Muddy sand } \\
\hline & Total & $\%$ & Total & $\%$ & Total & $0 \%$ & Total & $\%$ \\
\hline Ciliata & $>800$ & & 320 & & $>4000$ & & $>1000$ & \\
\hline Turbellaria & 1414 & 17.4 & 2488 & 16.6 & 462 & 12.9 & 262 & 1.2 \\
\hline Gastrotricha & 530 & 6.4 & 630 & 4.2 & 264 & 7.4 & 11 & \\
\hline Nematoda & 1809 & 21.8 & 2751 & 18.4 & 2175 & 60.8 & 20224 & 94.1 \\
\hline Archiannelida & 342 & 4.1 & 171 & & 41 & & 36 & \\
\hline Polychaeta & 64 & & 199 & & 17 & & 503 & 2.3 \\
\hline Copepoda & 3305 & 39.9 & 230 & & 359 & 10.0 & 123 & \\
\hline Nauplii & 544 & 6.6 & 113 & & 139 & & 235 & 1.1 \\
\hline Ostracoda & 183 & & 7868 & 52.5 & 110 & & 71 & \\
\hline Halacarida & & & 408 & 2.7 & 2 & & & \\
\hline Others & 87 & & 112 & & 8 & & 15 & \\
\hline
\end{tabular}

total number, together with the percentage of the dominant taxa from the four sediments for all methods, excluding the ciliates. The group "others" includes the following taxa: Halammobydra, rotifers, tardigrades, nemerteans, oligochaetes and bivalves. They were represented in only small numbers. 


\section{STATISTICAL ANALYSES}

Initial analyses of the raw data showed that the variance was proportional to the mean, for the different methods. Further analyses, therefore, were done on transformed data, using $\log _{10}(\mathrm{n})$, where $\mathrm{n}$ was the number of the raw data.

Two-way analyses of variance were conducted on the total fauna data (with the exception of the beach data), for each type of sediment, in order to test for differences between methods, and between levels in the tank of sediment. The interaction between levels and methods was used as the error term since there were no replicates in this analysis. Only in the muddy sand sample (Table 6) were significant differences between levels in the tank found. Elimination of samples from level A in this tank (which had significantly smaller numbers of animals than the other levels), rendered the differences between levels non-significant. Thus, the tanks of sediment could be considered homogenous (since differences between levels were not significant), and the four sam-

Table 3

Raw data and statistical analyses: total fauna (corresponding to Tables 7, 10 and Fig. 4a). Medium sand with fine sand, well sorted (medium sand). X: mean of transformed data; $\mathrm{S}^{2}$ : variance of transformed data; df: degrees of freedom; S.S.: sum of squares; M.S.: mean square; F: ratio; $\mathrm{p}$ : level of probability. * Significant at less than $\mathrm{p}=0.05$; ** less than $\mathrm{p}=0.01 ; * *$ less than $\mathrm{p}=0.001$. - Non significantly different means (within bars). + Preserved material used in elutriation. (Further explanations in the text)

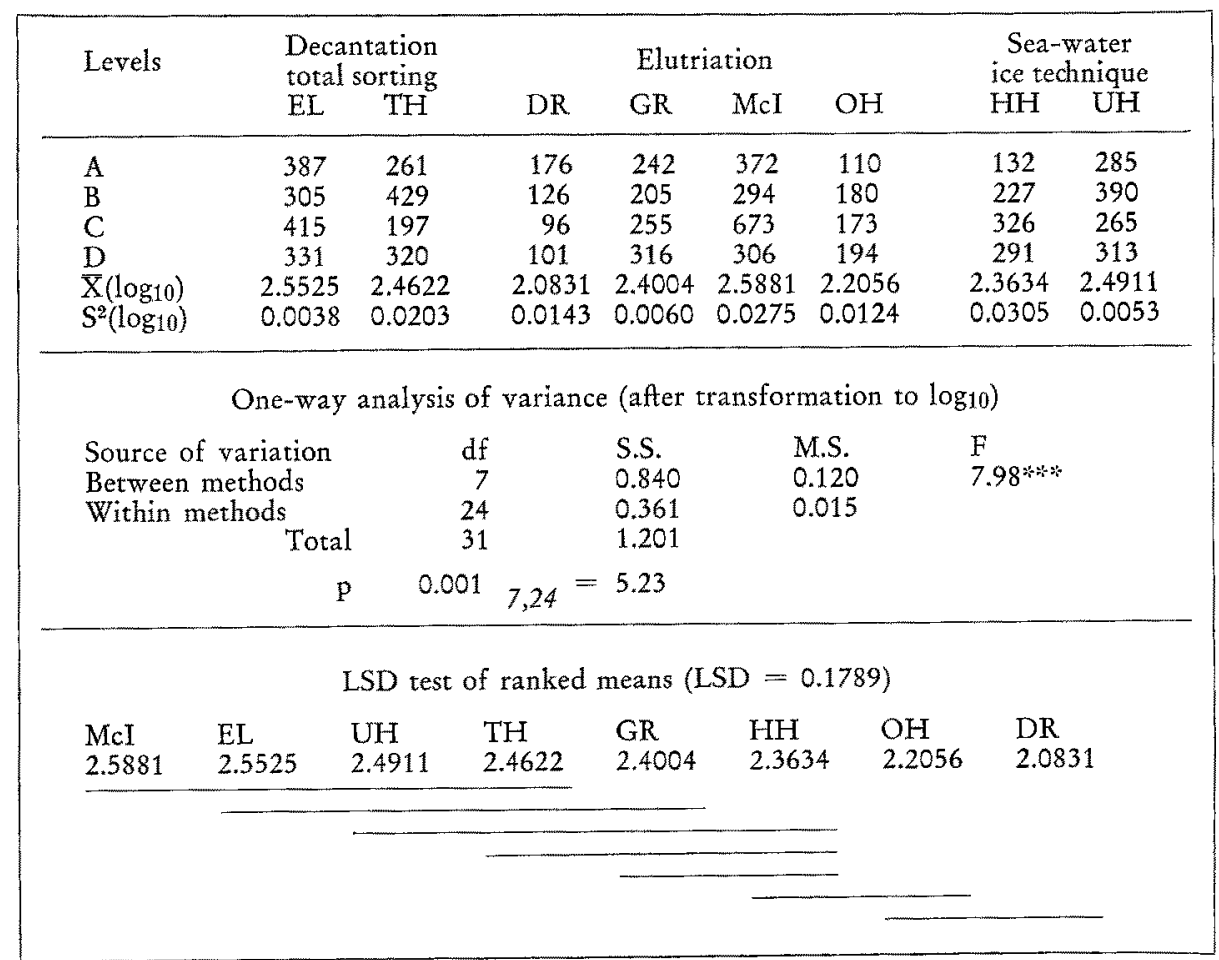


ples used as replicates, which had the additional advantage of increasing degrees of freedom in further statistical analyses.

One-way analyses of variance were conducted on the transformed data to compare (a) methods for total fauna data, (b) use of sea-water ice alone on total fauna data, (c) hard fauna (Nematoda, Copepoda, Ostracoda, Halacarida), (d) soft fauna (Turbellaria, Gastrotricha, Archiannelida, Polychaeta, Nemertea, and Halommobydra), and (e) Nematoda alone (the dominant taxon).

Since it was decided a priori to test for differences between methods, differences between the mean transformed numbers of animals were tested using the Least Significant Difference (LSD) test (SoKAL \& RoHLF 1969), where:

$$
\mathrm{LSD}=\tau_{(\mathrm{v})} \sqrt{\frac{2}{\mathrm{n}} \mathrm{MS}_{\text {within }}}
$$

and $t_{(v)}$ is the value of $t$ from standard tables for a probability $p=0.05$ and with ( $v$ ) degrees of freedom, where $v$ is the within group degrees of freedom from the analysis of variance table, $\mathrm{n}$ is the number of samples per group and MS within is the within group mean square from the analysis of variance table. In the following examples the means are ranked from left to right and non-significantly different means are included within bars. The LSD is subtracted successively from each mean until all means are included.

Table 4

Raw data and statistical analyses: total fauna (corresponding to Tables 8,11 and Fig. $4 \mathrm{~b}$ ). Coarse sand with shell gravel, fairly well sorted (coarse sand). (Explanations see Table 3 and text)

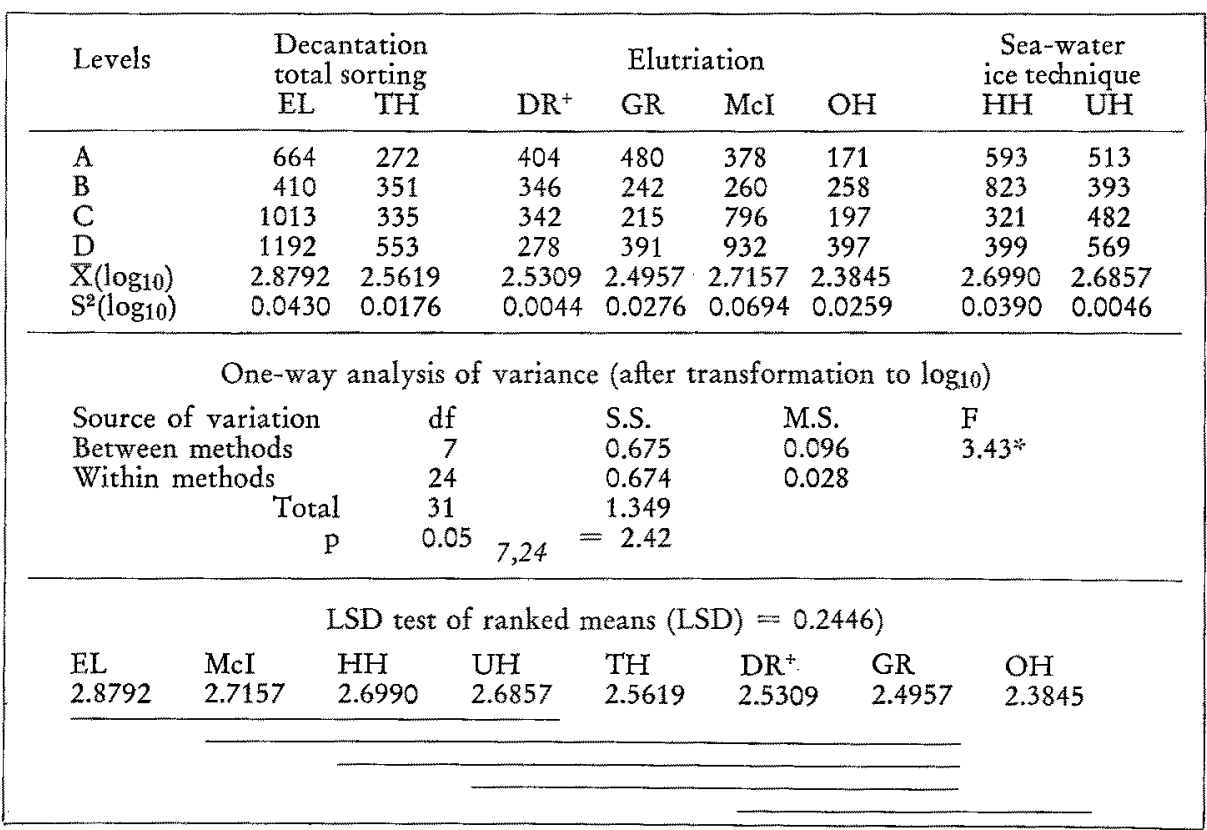




\section{COMPARISON AND EVALUATION OF SEPARATION METHODS}

For the general evaluation of the separation methods tested by our experiments, "Kendall's Tau rank correlation" was applied (SoKal \& Rohlf 1969). The various methods were ranked against numbers of organisms from total fauna data, Nematoda data, hard fauna and soft fauna data to give a total rank for the methods. Under this solely numerical comparison, decantation and elutriation ranked highest and sea-water ice treatment next, while elutriation with anaesthetization and the warm-water method were less effective. However, such comparison does not take into consideration that (1) the various animal groups are not separated with the same accuracy, (2) the organisms are collected alive in some methods and dead in others, (3) the separation efficiency differs from one sediment type to another and (4) the time required for concentration, sorting and counting is unequal. These topics will be discussed in the following paragraphs.

Table 5

Raw data and statistical analyses: total fauna (corresponding to Tables 9, 12 and Fig. 4c). Fine sand, well sorted (fine sand). (Explanations see Table 3 and text)

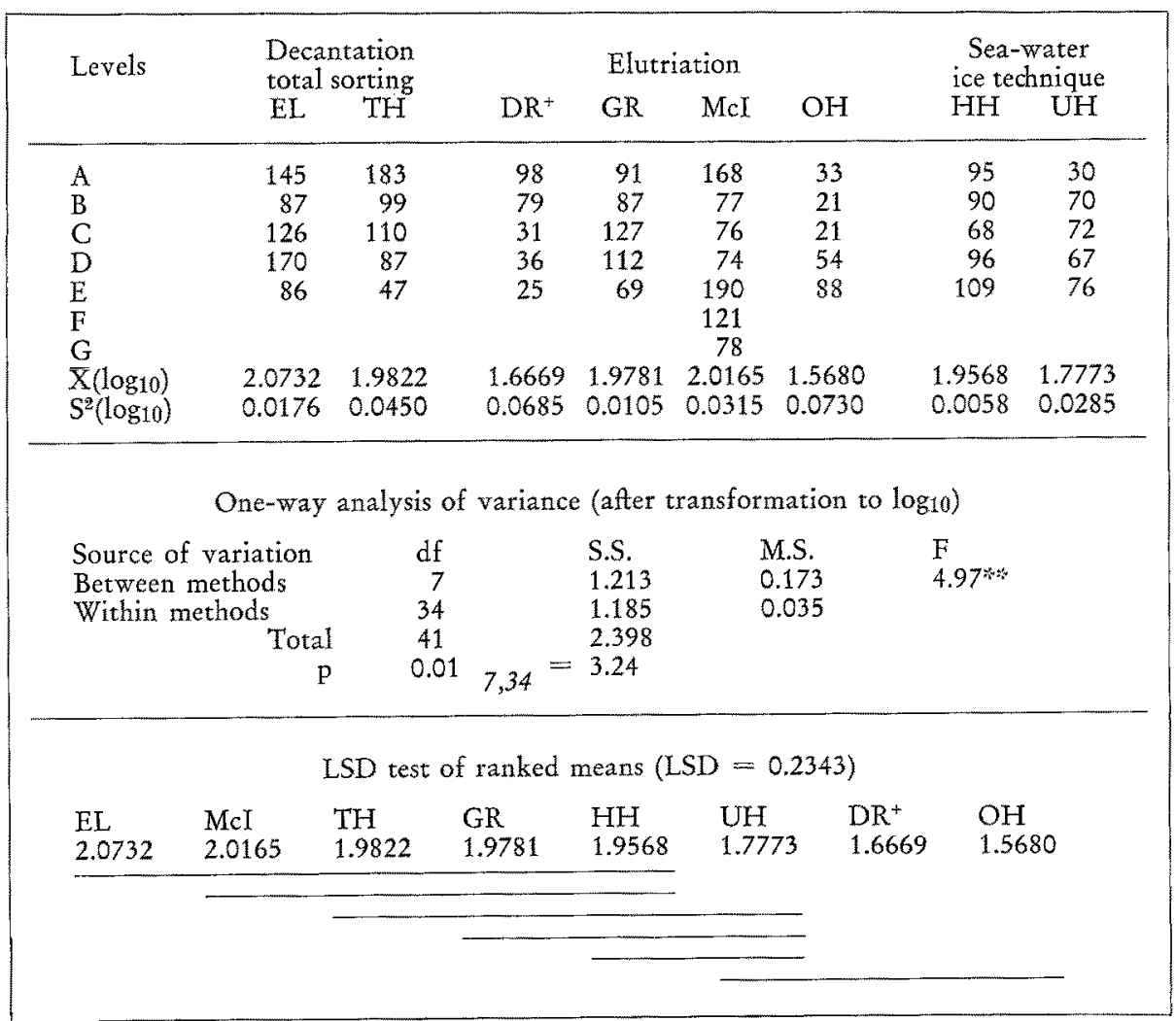




\section{Total fauna separation}

Investigations of benthic biocoenoses are generally concerned with the total fauna. Thus, we tried to separate the total meiofauna from our samples. The results are given in Tables 3-6. The statistical evaluation of the methods is demonstrated by the Least Significance Difference (LSD) test of ranked means. The non-significantly different means are included within the bars. In Table 3 the highest mean (McI) was not significantly different from (EL), (UH) or (TH) but was significantly better than (GR), $(\mathrm{HH}),(\mathrm{OH})$ and $(\mathrm{DR})$. Similarly (EL) was not different from (UH), (TH) and (GR) but better than $(\mathrm{HH}),(\mathrm{OH})$ and $(\mathrm{DR})$. The largest break occurred between $(\mathrm{HH})$ and $(\mathrm{OH})$ with three groups terminating here. The difference between the two sea-water ice procedures $(\mathrm{UH})$ and $(\mathrm{HH})$ resulted from the splitting of the total sample into three grain-size fractions by (UH) and consequently in a more thorough treatment.

Table 6

Raw data and statistical analyses, total fauna (corresponding to Fig. 4d). Medium sand, poorly sorted (muddy sand). (Explanations see Table 3 and text)

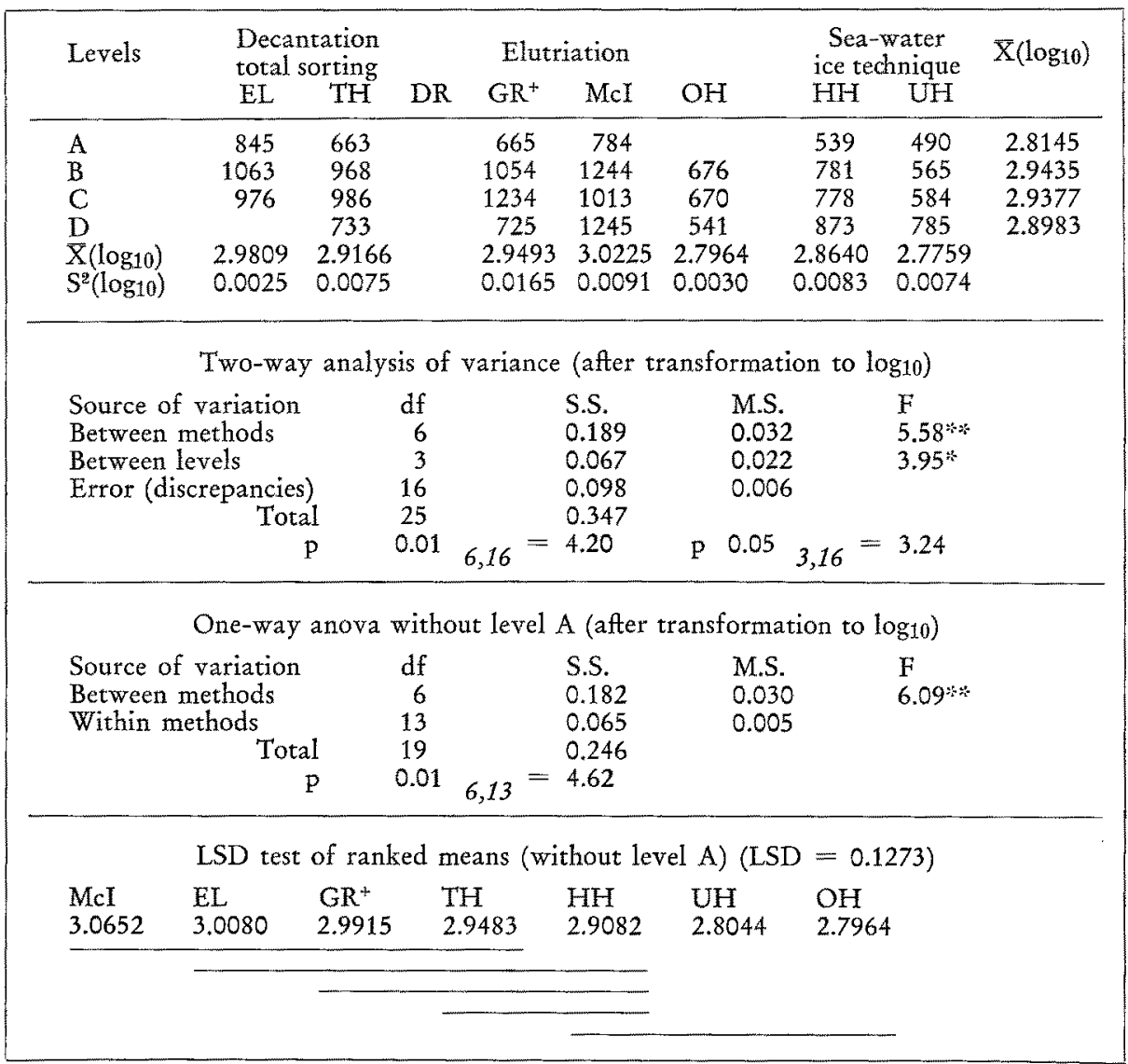


The preservation methods (McI), (EL) and (TH) are all included in the top group with one sea-water ice method (UH). Anaesthetization (GR) and the second sea-water ice group were marginally inferior but the warm-water method $(\mathrm{OH})$ and live elutriation (DR) were significantly worse.

Tables 4, 5 and 6 show a similar pattern with the preservation methods (EL), $(\mathrm{McI})$ and $(\mathrm{TH})$ again within the top group together with the two sea-water ice methods (UH), (HH) (Table 4). Preservation methods were used by (DR) (Tables 4 and 5) and by (GR) (Table 6) instead of live extraction, resulting in a higher ranking. In the muddy sand (Table 6), the sea-water ice methods are clearly less effective.

The warm-water elutriation, especially designed for the isolation of nematodes and ostracods, is not suitable to cover the total fauna.

In general, elutriation and decantation rank highest in our experiments for the separation of total fauna.

\section{Living and dead separation}

It was one of our intentions at the Helgoland meeting, to compare the efficiencies of methods for the separation of living and preserved meiofauna. The question posed

Table 7

Raw data and statistical analyses: hard fauna (corresponding to Tables 3, 10 and Fig. 4a). Medium sand with fine sand, well sorted (medium sand). (Explanations see Table 3 and text)

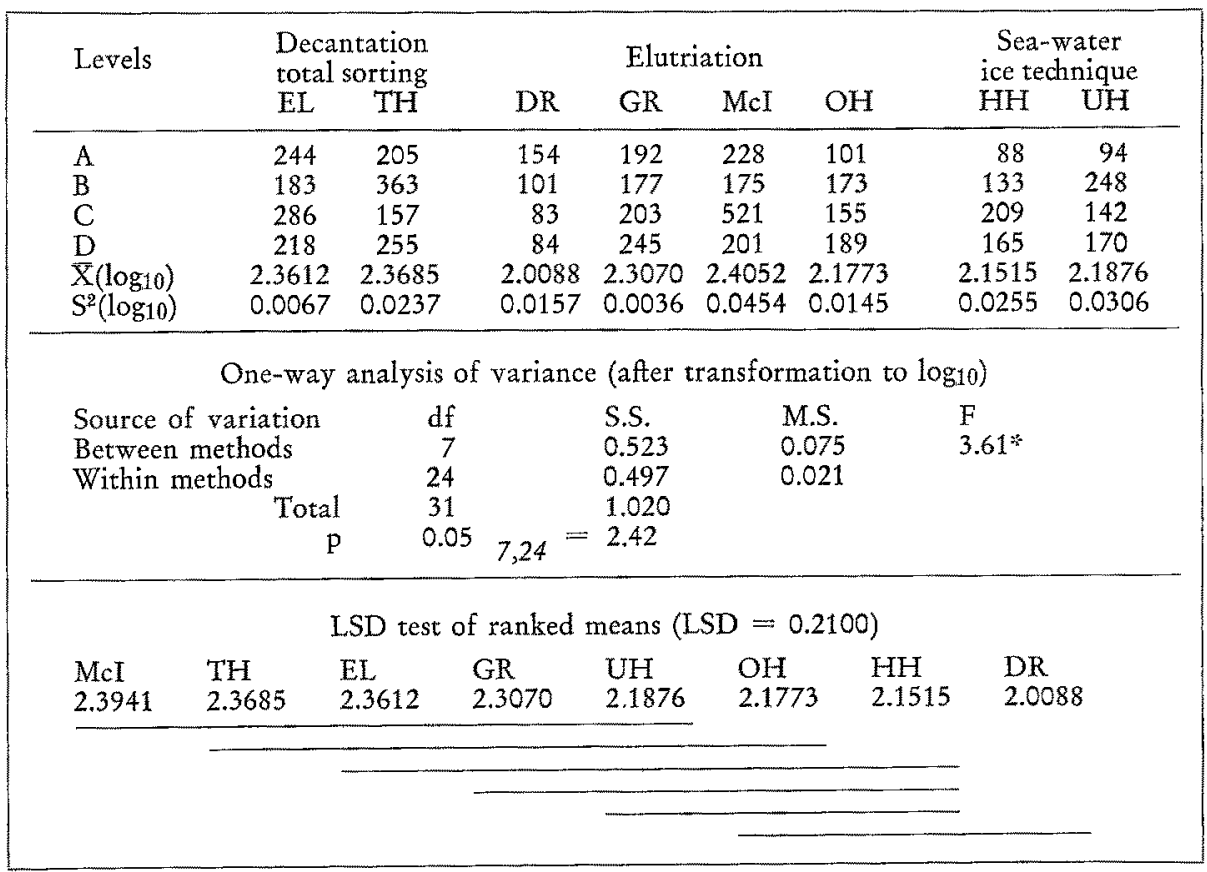


Table 8

Raw data and statistical analyses: hard fauna (corresponding to Tables 4, 11 and Fig. 4b). Coarse sand with shell gravel, fairly well sorted (coarse sand). (Explanations see Table 3 and text)

\begin{tabular}{|c|c|c|c|c|c|c|c|c|}
\hline \multirow[t]{2}{*}{ Levels } & \multicolumn{2}{|c|}{$\begin{array}{l}\text { Decantation } \\
\text { total sorting }\end{array}$} & \multicolumn{4}{|c|}{ Elutriation } & \multicolumn{2}{|c|}{$\begin{array}{l}\text { Sea-water } \\
\text { ice technique }\end{array}$} \\
\hline & $\mathrm{EL}$ & TH & DR & GR & McI & $\mathrm{OH}$ & $\mathrm{HH}$ & UH \\
\hline A & 567 & 197 & 356 & 430 & 178 & 170 & 452 & 407 \\
\hline$B$ & 317 & 291 & 289 & 205 & 192 & 257 & 345 & 271 \\
\hline $\mathrm{C}$ & 759 & 287 & 307 & 167 & 578 & 187 & 238 & 377 \\
\hline & 649 & 436 & 179 & 328 & 803 & 394 & 292 & 456 \\
\hline $\bar{X}\left(\log _{10}\right)$ & 2.7367 & 2.4639 & 2.4381 & 2.4209 & 2.5501 & 2.3769 & 2.5087 & 2.5697 \\
\hline$S^{2}\left(\log _{10}\right)$ & 0.0274 & 0.0198 & 0.0167 & 0.0351 & 0.1105 & 0.0271 & 0.0138 & 0.0094 \\
\hline \multicolumn{9}{|c|}{ one-way analysis of variance (after transformation to $\log _{10}$ ) } \\
\hline \multirow{4}{*}{\multicolumn{2}{|c|}{$\begin{array}{l}\text { Source of variation } \\
\text { Between methods } \\
\text { Within methods } \\
\text { Total }\end{array}$}} & \multirow{4}{*}{$\begin{array}{r}\mathrm{df} \\
7 \\
24 \\
31\end{array}$} & & S.S. & \multirow{4}{*}{\multicolumn{2}{|c|}{$\begin{array}{l}\text { M.S. } \\
0.051 \\
0.033\end{array}$}} & \multirow{4}{*}{\multicolumn{2}{|c|}{$\begin{array}{l}\mathrm{F} \\
1.57 \text { n.s. }\end{array}$}} \\
\hline & & & & 0.358 & & & & \\
\hline & & & & 0.780 & & & & \\
\hline & & & & 1.114 & & & & \\
\hline
\end{tabular}

Table 9

Raw data and statistical analyses: hard fauna (corresponding to Tables 5, 12 and Fig. 4c). Fine sand, well sorted (fine sand). Explanations see Table 3 and text)

\begin{tabular}{|c|c|c|c|c|c|c|c|c|c|}
\hline \multirow[t]{2}{*}{ Levels } & \multicolumn{2}{|c|}{$\begin{array}{l}\text { Decantation } \\
\text { total sorting }\end{array}$} & \multicolumn{5}{|c|}{ Elutriation } & \multicolumn{2}{|c|}{$\begin{array}{l}\text { Sea-water } \\
\text { ice technique }\end{array}$} \\
\hline & & & $\mathrm{DR}^{+}$ & GR & $\mathrm{McI}$ & \multicolumn{2}{|c|}{$\mathrm{OH}$} & \multicolumn{2}{|c|}{$\begin{array}{l}\text { ice technque } \\
\mathrm{HH} \text { UH }\end{array}$} \\
\hline A & 96 & 154 & 72 & 65 & 126 & & 27 & 76 & 23 \\
\hline $\mathrm{B}$ & 54 & 77 & 66 & 70 & 69 & & 19 & 67 & 49 \\
\hline C & 96 & 77 & 19 & 112 & 62 & & 20 & 56 & 83 \\
\hline $\mathrm{D}$ & 128 & 64 & 34 & 94 & 50 & & 50 & 76 & 48 \\
\hline $\mathrm{E}$ & 62 & 38 & 19 & 60 & 156 & & 37 & 71 & 57 \\
\hline & \multirow[b]{2}{*}{1010} & \multirow[b]{3}{*}{1.8693} & & & 99 & & & & \\
\hline & & & & & 60 & & & \\
\hline $\bar{X}\left(\log _{10}\right)$ & \multirow{2}{*}{$\begin{array}{l}1.9193 \\
0.0236 \\
\end{array}$} & & 1.5531 & 1.8917 & 1.9139 & \multirow{2}{*}{\multicolumn{2}{|c|}{$\begin{array}{l}1.5299 \\
0.0804\end{array}$}} & 1.8374 & 1.6816 \\
\hline$S^{2}\left(\log _{10}\right)$ & & 0.0474 & 0.0786 & 0.0131 & 0.0341 & & & 0.0030 & 0.0411 \\
\hline \multicolumn{10}{|c|}{ One-way analysis of variance (after transformation to $\log _{10}$ ) } \\
\hline \multirow{3}{*}{\multicolumn{2}{|c|}{$\begin{array}{l}\text { Source of variation } \\
\text { Between methods } \\
\text { Within methods }\end{array}$}} & \multirow{3}{*}{$\begin{array}{r}\mathrm{df} \\
7 \\
34\end{array}$} & & S.S. & \multirow{2}{*}{\multicolumn{3}{|c|}{ M.S. }} & \multirow{2}{*}{\multicolumn{2}{|c|}{$\begin{array}{l}\text { F } \\
3.44 \%\end{array}$}} \\
\hline & & & & 0.960 & & & & & \\
\hline & & & & 1.354 & \multirow{2}{*}{\multicolumn{3}{|c|}{0.040}} & & \\
\hline & Total & 41 & & 2.313 & & & & & \\
\hline & p & 0.05 & $7,34=$ & 2.55 & & & & & \\
\hline \multicolumn{10}{|c|}{ LSD test of ranked means $(\mathrm{LSD}=0.2505)$} \\
\hline \multirow{4}{*}{$\begin{array}{l}\text { EL } \\
1.9193\end{array}$} & $\mathrm{McI}$ & GR & & $\mathrm{HH}$ & $\mathrm{UH}$ & & \multirow{4}{*}{$\begin{array}{l}\mathrm{DR}^{+} \\
1.5531\end{array}$} & \multirow{2}{*}{\multicolumn{2}{|c|}{$\begin{array}{l}\mathrm{OH} \\
1.5299\end{array}$}} \\
\hline & 1.9139 & 1.8917 & 1.8693 & 1.8374 & 1.68 & & & & \\
\hline & \multicolumn{6}{|c|}{$-2-1-2=-2$} & & & \\
\hline & \multicolumn{6}{|c|}{$-1-2$} & & & \\
\hline
\end{tabular}


was, to what extent can living extractions be considered as quantitative methods? The live methods were the sea-water ice treatments $(\mathrm{HH}),(\mathrm{UH})$, elutriation (DR), and elutriation with anaesthetization (GR). Live elutriation without anaesthetization is less effective, as obviously many organisms remain attached to the sediment grains during the procedure. Better results were obtained with an anaesthetic in a closedcircuit system (GR: Tables 3-5).

The sea-water ice methods involved both sea-water ice treatment followed by preservation and staining of the sand residue, a two-part technique (Tables 3-6). They rank at about the same level as elutriation with anaesthetic (GR). Furthermore, the effectiveness of sea-water ice without additional preservation, was examined. By this test, the $(\mathrm{HH})$ method, which involves exposing a larger sediment surface to ice than in the (UH) method, is clearly more effective. However, as sole treatments, both are less efficient than preservation and elutriation or decantation (McI) and (EL).

The important advantages of live extraction by the sea-water ice treatment are the isolation of meiofauna (especially the soft fauna) in unharmed condition, and the almost quantitative isolation of ciliates and flagellates, not recovered with any other method (Tables 1 and 2).

Table 10

Raw data and statistical analyses: soft fauna (corresponding to Tables 3, 7 and Fig. 4a). Medium sand with fine sand, well sorted (medium sand). (Explanations see Table 3 and text)

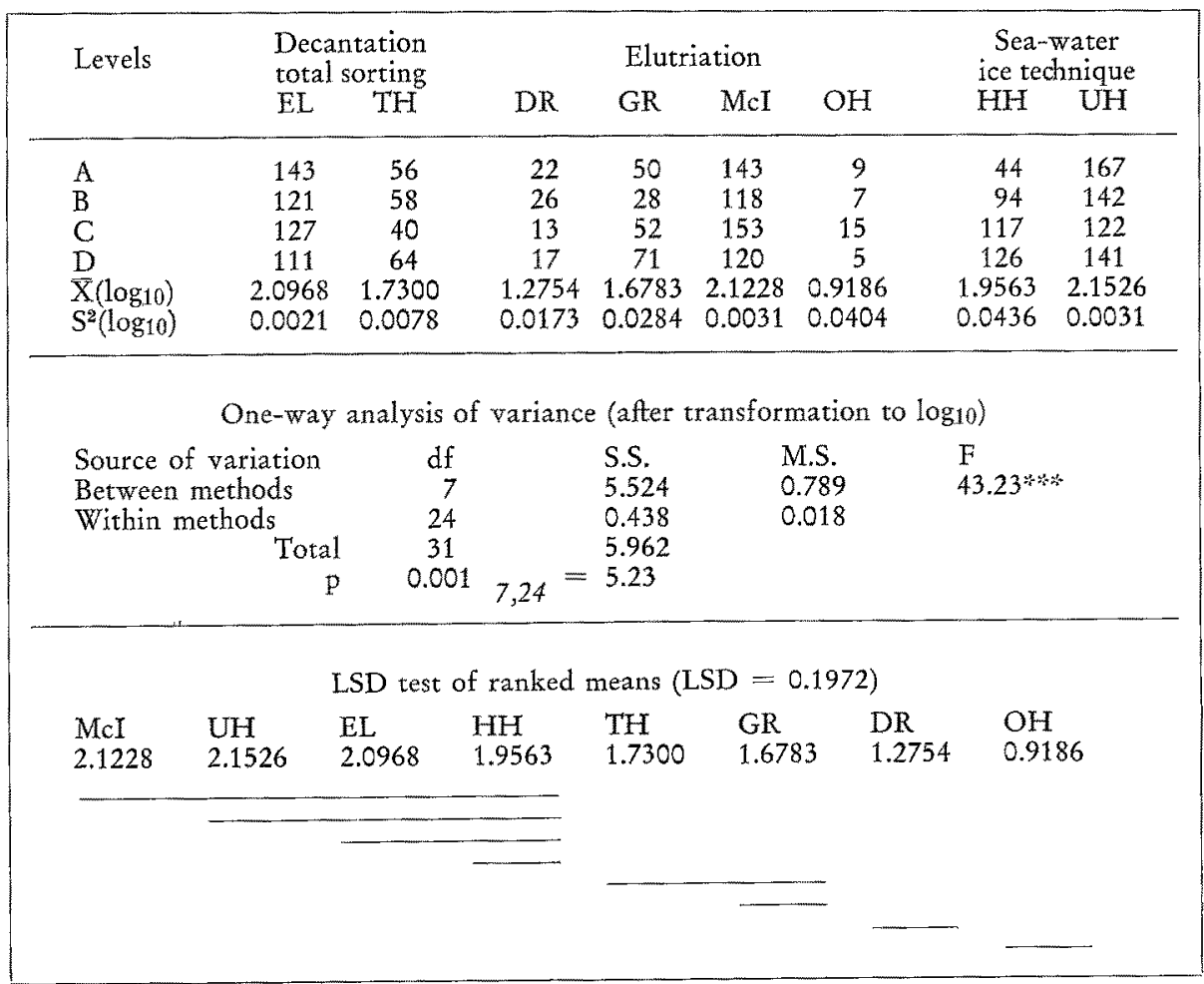




\section{Hard and soft fauna separation}

It was thought that some methods may be more effective in extracting hard fauna (Nematoda, Ostracoda, Copepoda and Halacarida), whilst others may be better for soft fauna (Turbellaria, Gastrotricha, Archiannelida, Polychaeta, Nemertea and solitary Cuidaria). Tables 7,8 and 9 show the data for hard fauna and Tables 10,11 and 12 show the data for soft fauna. The split into hard and soft fauna was not made for muddy sand since the fauna was composed almost exclusively of nematodes, i.e. the results correspond more or less with the total fauna (Table 6).

Tables 7 and 9 indicate that there was little difference between methods, only (DR) in Table 7 and (DR) and (OH) in Table 9 being significantly less effective. In Table 8 , however, the two-way analysis of variance showed a high between-level variance and a non-significant between-method variance. Consideration of the raw data demonstrated that the large variation in numbers of Ostracoda probably accounted for the fact that no difference could be detected between methods (Table 8).

Tables 10, 11 and 12 show that for the soft fauna the preservation methods of $(\mathrm{EL}),(\mathrm{McI})$ and the sea-water ice methods $(\mathrm{UH})$ and $(\mathrm{HH})$ were consistently the most

Table 11

Raw data and statistical analyses: soft fauna (corresponding to Tables 4, 8 and Fig. 4b). Coarse sand with shell gravel, fairly well sorted (coarse sand). (Explanations see Table 3 and text)

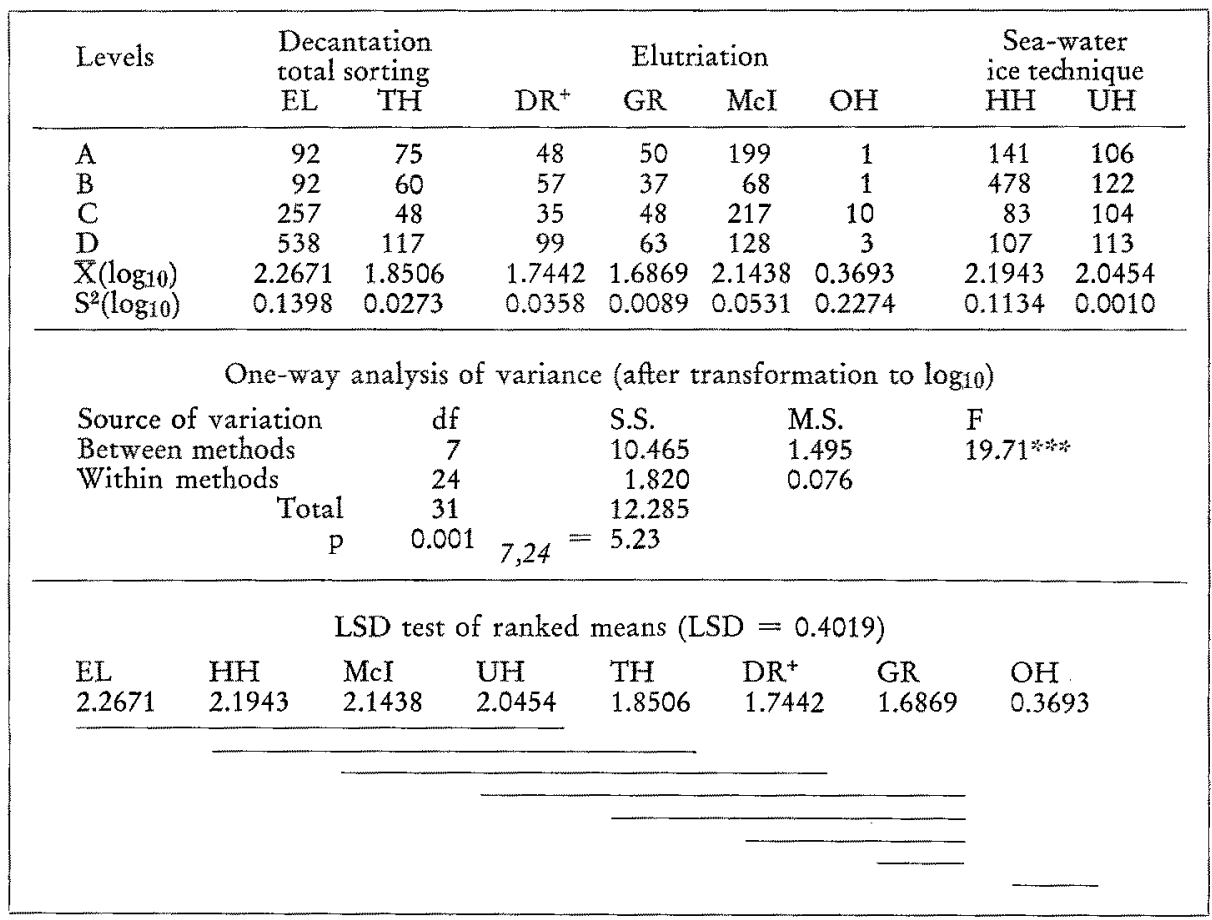


successful. The preservation and direct sorting method (TH) was more variable whilst anaesthetization (GR), the $\left(\mathrm{DR}^{+}\right)$preservation and warm-water $(\mathrm{OH})$ methods were significantly less effective. However, one must consider that preservation does not allow accurate identification of soft fauna representatives. Ciliates, for instance, may easily be confused with turbellarians.

\section{Sediment types and time loss in separation}

Efficiency of all concentration methods decreases for total fauna with decreasing mean grain-size distribution and increasing detritus content, and consequently more efforts and time are required for sorting. For the sea-water ice treatment this may be explained by the reduction of the microporal system. In decantation and elutriation, the "lighter" particles are not sufficiently well separated from the fauna.

In this context it is imperative to take into consideration the time loss for each method. A rough comparison of total time loss results in the following order: elutriation - sea-water ice treatment - decantation.

\section{Table 12}

Raw data and statistical analyses: soft fauna (corresponding to Tables 5,9 and Fig. 4c) Fine sand, well sorted (fine sand). (Explanations see Table 3 and text)

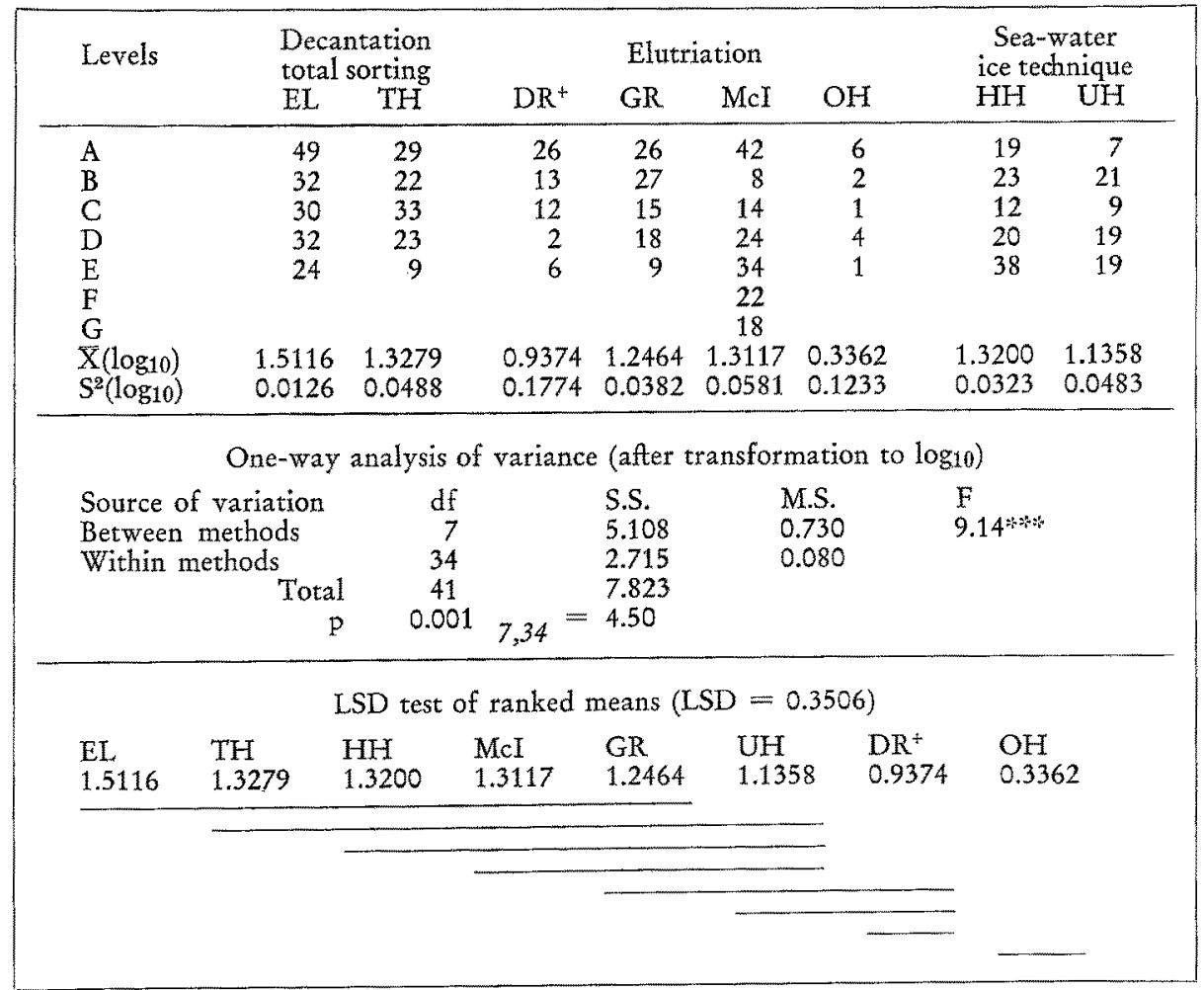


In general, elutriation and decantation are the quicker concentration procedures, while in sea-water ice treatment the time required depends on the melting process.

Concerning sorting and counting, a surprisingly quick procedure was demonstrated by direct in situ counting (p. 180). Contrary to this, other participants counted the fauna by picking out with pipettes, which is much more time consuming. Differences in time loss relate to the sediment quota in the counting dish. Under this aspect seawater ice treatment ranges over elutriation, decantation and total sorting.

\section{SUMMARY}

1. This paper presents the results of a meeting on the evaluation of quantitative procedures for the separation of meiofauna, held at the Marine Station of the Biologische Anstalt Helgoland, in May 1972. Close co-operation on the part of the participants (p. 194) has allowed assessment of advantages and disadvantages of the separation methods applied. The time needed for preserved methods can be reduced by changing to scanning rather than picking out for sorting and counting.

2. Sorting without concentrations: This method is suitable for very fine-grained sediments, oozes; it is generally applied for preserved samples; adequate for hard fauna; insufficient for soft fauna; very time consuming.

3. Decantation: Suitable for sandy sediments; generally applied for preserved samples; adequate for hard fauna; insufficient for soft fauna; time consuming.

4. Elutriation: Suitable for sandy sediments; for unpreserved samples only with anaesthetization, more effective with preserved samples; limited for total live fauna. With preserved samples, adequate for hard fauna; insufficient for soft fauna; quick method.

5. Warm-water elutriation: Suitable for sandy sediments; designed for live hard fauna (especially nematodes, ostracods); quick method.

6. Sea-water ice treatment: Suitable for sandy sediments with microporal structure; only for live extraction; limited for hard fauna; well suited for soft fauna (including ciliates and flagellates); time consuming.

Acknowledgements. Travelling funds for all participants were granted by their National Agencies. Substantial support by the Biologische Anstalt Helgoland and financial aid by the "Sonderforschungsbereich 94 - Meeresforschung an der Universität Hamburg" is gratefully acknowledged. Thanks are due to Dr. K. FIGGE, Deutsches Hydrographisches Institut (Hamburg), for the grain-size analyses.

\section{LITERATURE CITED}

ARLT, G., 1973. On the vertical and horizontal microdistribution of the meiofauna in the Greifswalder Bodden. Oikos (Suppl.) 14 (in press).

Borsseau, J. P., 1957. Technique pour l'étude quantitative de la faune interstitielle des sables. C. r. Congr. Socs sav. Paris Sect. Sci., 117-119. 
ELmGREN, R., 1973. Methods of sampling sublittoral soft bottom meiofauna. Oikos (Suppl.) 14 (in press).

Hulnsgs, N. C. (Ed.), 1971. Proceedings of the First International Conference on Meiofauna. Smithson. Contr. Zool. 76, 1-205.

- \& Grax, J. S. (Eds), 1971. A manual for the study of meiofauna. Smithson. Contr. Zool. $78,1-83$.

Russeil, F. S. \& Colman, T. E., 1931. The zooplankton I. Gear, methods and station lists. Scient. Rep. Gt. Barrier Reef Exped. 2 (2), 1-35.

Sokal, R. P. \& Roht., F. T., 1969. Biometry. Freeman, San Francisco, 776 pp.

THIEL, H., 1966. Quantitative Untersuchungen über die Meiofauna des Tiefseebodens. Veröff. Inst. Meeresforsch. Bremerh. (Sonderbd) 2, 131-148.

UhLIG, G., 1964. Eine einfache Methode zur Extraktion der vagilen, mesopsammalen Mikrofauna. Helgoländer wiss. Meeresunters. 11, 178-185.

- 1968. Quantitative methods in the study of interstitial fauna. Trans. microse. Soc. 87, 226-232.

\section{LIST OF PARTICIPANTS}

BARTELT, H., Institut für Hydrobiologie und Fischereiwissenschaft der Universität Hamburg, 2 Hamburg 50, Palmaille 55, Federal Republic of Germany.

DrzycimsKi, I., Department of Oceanography and Marine Biology, Szczecin 5, ul.K. Krolewieza 3, Poland.

ELMGREN, R., Zoologiska Institutionen, Universitetet i Stockholm, Askölaboratoriet, Box 58, S-15013 Trosa, Schweden.

Gray, J. S., Wellcome Marine Laboratory, The University of Leeds, Robin Hood's Bay, Yorkshire, England.

Hartwig, E., II. Zoologisches Institut der Universität Göttingen, 34 Göttingen, Berliner Straße 28, Federal Republic of Germany.

Hoxfrol. , S., II. Zoologisches Institut der Universität Göttingen, 34 Göttingen, Berliner Straße 28, Federal Republic of Germany.

Martin, D., Biologische Anstalt Helgoland (Meeresstation), 2192 Helgoland, Federal Republic of Germany.

MCINTYRE, A. D., Department of Agriculture and Fisheries for Scotland, Marine Laboratory, P. O. Box 101, Victoria Road, Aberdeen AB9 8DB, Scotland.

Murison, D., Department of Agriculture and Fisheries for Scotland, Marine Laboratory, P. O. Box 101, Victoria Road, Aberdeen AB9 8DB, Scotland.

NowaK, K., Institut für Hydrobiologie und Fischereiwissenschaft der Universität Hamburg, 2 Hamburg 50, Palmaille 55, Federal Republic of Germany.

OHDE, J., Institut für Hydrobiologie und Fischereiwissenschaft der Universität Hamburg, 2 Hamburg 50, Palmaille 55, Federal Republic of Germany.

SarilnNG, G., Biologische Anstalt Helgoland (Meeresstation), 2192 Helgoland, Federal Republic of Germany.

THIEL, H., Institut für Hydrobiologie und Fischereiwissenschaft det Universität Hamburg, 2 Hamburg 50, Palmaille 55, Federal Republic of Germany.

Uhile, G., Biologische Anstalt Helgoland (Meeresstation), 2192 Helgoland, Federal Republic of Germany.

\section{Unable to attend:}

ARLT, G., Fachbereich Meeres- und Fischereibiologie, Sektion Biologie der Universität Rostock, 25 Rostock, Freiligrathstraße 7/8, German Democratic Republic.

SwEDMARK, B., Kristineberg Zoologiska Station, S-45034 Fiskebäckskil, Sweden. 
Visitors to the meeting:

Gerlach, S., Institut für Meeresforschung, 285 Bremerhaven, Am Handelshafen 12, Federal Republic of Germany.

Juario, J. V., Institut für Meeresforschung, 285 Bremerhaven, Am Handelshafen 12, Federal Republic of Germany.

Por, F. D., Department of Zoology, Hebrew University, Jerusalem, Israel.

RACHOR, E., Institut für Meeresforschung, 285 Bremerhaven, Am Handelshafen 12, Federal Republic of Germany.

WALTER, M., Institut für Hydrobiologie und Fischereiwissenschaft der Universität Hamburg, 2 Hamburg 50, Palmaille 55, Federal Republic of Germany.

First authors's address: Dr. G. UhLIG

Biologische Anstalt Helgoland (Meeresstation)

2192 Helgoland

Federal Republic of Germany 